\title{
Lives in the Asylum Record, 1864 to 1910: Utilising Large Data Collection for Histories of Psychiatry and Mental Health
}

\author{
ANGELA MCCARTHY $^{1 *}$, CATHARINE COLEBORNE ${ }^{2}$, MAREE O'CONNOR $^{3}$ \\ and ELSPETH KNEWSTUBB ${ }^{4}$ \\ ${ }^{1}$ Department of History and Art History, University of Otago, Dunedin, New Zealand \\ ${ }^{2}$ School of Humanities and Social Science, Faculty of Education and Arts, University of Newcastle, \\ University Drive, Callaghan, NSW 2308, Australia \\ ${ }^{3}$ Independent researcher, Stopford Road, RD3 Matamata, 3473, New Zealand \\ ${ }^{4}$ Independent researcher, 4 Saddleback Grove, Karori, Wellington 6012, New Zealand
}

\begin{abstract}
This article examines the research implications and uses of data for a large project investigating institutional confinement in Australia and New Zealand. The cases of patients admitted between 1864 and 1910 at four separate institutions, three public and one private, provided more than 4000 patient records to a collaborative team of researchers. The utility and longevity of this data and the ways to continue to understand its significance and contents form the basis of this article's interrogation of data collection and methodological issues surrounding the history of psychiatry and mental health. It examines the themes of ethics and access, record linkage, categories of data analysis, comparison and record keeping across colonial and imperial institutions, and constraints and opportunities in the data itself. The aim of this article is to continue an ongoing conversation among historians of mental health about the role and value of data collection for mental health and to signal the relevance of international multi-sited collaborative research in this field.
\end{abstract}

Keywords: History of psychiatry, Categories of data analysis, Longitudinal record linkage, Ethics and access, Quantitative and qualitative analysis, Collaborative research

\section{Introduction}

Medical histories have increasingly been written at the intersections of social and cultural histories of institutions and their practices. The imperial world of insanity and its

* Email address for correspondence: angela.mccarthy@ otago.ac.nz

Our research, which this article retrospectively examines, was generously supported by the Royal Society of New Zealand Marsden Fund, 08-UOO-167 SOC. 
confinement included institutions for the insane in colonial societies. The voluminous case history data generated by these past institutions - namely hospitals for the insane - has tended to shape and characterise studies of mental illness and its treatments, with a particular focus on the nineteenth century. Scholars have considered administrative practices and the ensuing production of social and political meanings about insanity and its populations in those sites. ${ }^{1}$ This now rich scholarship attests to the value of the enduringly interesting themes emerging from large colonial social institutions and their patient populations. The potential of these institutions to enhance our historical understandings of past peoples and their struggles is enormous: the archive contains 'histories that refract light between colony and "home", the sane and the mad'. ${ }^{2}$ Such records provide opportunities of interpretation, access to 'experiences' of mental health and illness, and to the worlds of peoples before our own era of mental health policy and practice. $^{3}$

Despite their benefits, historians have been alert to the difficulties in using patient records. These 'lives in the record' are sometimes understood as silenced, obscured or invisible because of the power relations of the institutions themselves. Historians have grappled with the inconsistencies and flaws of psychiatric patient records, calling them 'innately jaundiced'. ${ }^{4}$ Historian Barbara Taylor writes that psychiatric case histories have been disappearing in the present, a result of the widespread process of institutional closures in the late twentieth century. Yet, suggests Taylor, 'without history, people disappear'. 5

While recognising the centrality of psychiatric patient case records and the associated difficulties in using them, the methodological processes involved in their collection and interpretation and in the ongoing data management by historians have received relatively limited focused critical attention. We argue that, while historians have talked about the relevance and use of patient records, weighing up their status, and investigating the intellectual problems they present, they have not always talked openly about their own strategies in sorting, storing, analysing and making sense of large data sets (for further elaboration, see our discussion under Statistical Approaches below). This problem, too, shapes historical thinking about the case record, its provenance and utility. This article examines the questions that circulate around the use of patient case data within an historiographical discussion about the histories of mental health and patient confinement in the British world.

We take recent examples of a large project involving the use of patient cases from four institutions across New Zealand and Victoria, Australia, to ask new questions about patient case data and its potential for historians. These questions include the mixed methodology

\footnotetext{
${ }^{1}$ Examples include studies of India, the African colonies, and Canada. See James H. Mills, Madness, Cannabis and Colonialism: The 'Native-Only' Lunatic Asylums of British India, 1857-1900 (London and New York: Macmillan/St Martins, 2000); Sloane Mahone and Megan Vaughan (eds), Psychiatry and Empire (Houndmills, Basingstoke and New York: Palgrave Macmillan, 2007). See also Catharine Coleborne, Madness in the Family: Insanity and Institutions in the Australasian Colonial World, 1860-1914 (Houndmills, Basingstoke and New York: Palgrave Macmillan, 2010); Leonard Smith, Insanity, Race and Colonialism: Managing Mental Disorder in the Post-Emancipation British Caribbean, 1838-1914 (Houndmills, Basingstoke and New York: Palgrave Macmillan, 2014).

${ }^{2}$ Sally Swartz, 'Colonial Lunatic Asylum Archives: Challenges to Historiography', Kronos, 34 (2008), 302.

${ }^{3}$ Sally Swartz, 'Lost Lives: Gender, History and Mental Illness in the Cape, 1891-1910', Feminism and Psychology, 9, 2 (1999), 152-8.

4 Jonathan Andrews, 'Case Notes, Case Histories, and the Patient's Experience of Insanity at Gartnavel Royal Asylum, Glasgow, in the Nineteenth Century', Social History of Medicine, 11, 2 (1998), 266.

${ }^{5}$ Barbara Taylor, The Last Asylum: A Memoir of Madness in Our Times (London: Penguin, 2014), 268.
} 
which is now common in social histories of the insane: the blending of quantitative and qualitative analyses of data. Other themes examined here include the questions of patient case data management through databases, of ethics and access, of interpretive tools and modes of 'reading' cases using categories of data analysis, and of the use of ancillary sources and record linkage. We suggest that these themes provide useful models for historians seeking ways to enhance their use of similar data in other contexts. Our approach also demonstrates innovation in adopting a multi-sited approach to a field which typically confines itself to studies of single institutions when utilising a large body of patient data. The wider context here is a well-established field of inquiry, but one that has also raised new and largely unanswered questions about archival source materials and their international significance.

In addition, the overlapping concerns of social and cultural histories embedded in this article - the use of a large collection of primary source data, and modes of analysis and interpretation - remind us of the need to constantly refine our approaches and tools in the study of medical histories. Therefore, this article makes a series of new interventions into our understandings of collaborative, cross-institutional research, and aims to incite a larger conversation about the use of large data in medical-historical research. We start with some historiographical background to better situate this conversation, and to locate our own study globally. We move from statistical methods to qualitative analysis, and we then assess our project's own benefits and limitations before proceeding to an examination of the use of analytical categories and the value and complications of record linkage. Overall, we conclude that the challenges posed by projects based on a large multi-sited data sample actually generate exciting and stimulating questions about the uses of archival data for medical history.

\section{Historiography: Data Collection for the Histories of Psychiatry and Mental Health}

\section{Statistical Approaches}

Statistics have always been important in the past and present study of insanity. This includes the use of quantifiable data from asylum superintendents who sought to categorise patients and their forms of madness, as well as other details about them such as age, marital condition, native country, length of residence and occupation. Such statistics could be used by alienists to examine differences within and between countries, and situate their findings in a comparative and transnational field of medical knowledge. ${ }^{6}$ Historians of medicine likewise use statistics to examine the socio-demographic characteristics of patients but do so by largely drawing on asylum records to create their own populations, rather than relying on published aggregate data. We outline here four substantial studies that have used patient files to construct large datasets and some of their key findings. These proved useful to our endeavour in addressing similar themes about migration and ethnicity and their wider methodological approaches.

In a significant publication in 1932, Örnulv Ödegaard outlined a different methodological approach to the study of insanity from that of his predecessors. While earlier analysts typically compared the native and foreign-born incidence of insanity in the United States

\footnotetext{
${ }^{6}$ Angela McCarthy, 'Future Directions for the Study of Migration and Ethnicity in New Zealand: Comparative, Transnational, and Multidisciplinary Approaches to Records of Insanity', Journal of New Zealand Studies, 9 (2010), 79-98.
} 
with a focus on psychoses, Ödegaard elected instead to compare Norwegians in the United States with their counterparts in Norway. He did so to counteract 'racial' differences and chose to focus on the Rochester Hospital at Rochester and the Federal Insane Asylum at Oslo. Given the many thousands of patients admitted to these institutions between 1889 and 1928, Ödegaard extracted information for every second or third case giving him around 50 admissions each year (half male and half female). Overall, he compared 1995 cases from Norway with 1067 in America, with a key focus on whether the potentially mentally unstable were more likely to migrate or whether the trauma of migration generates mental illness. To examine this central question, Ödegaard adopted a further methodological approach: the decision to undertake his own diagnoses based on these patient records. ${ }^{7}$

Richard W. Fox, by contrast, drew on court records to extract data relating to 12150 individuals committed for insanity in San Francisco between 1906 and 1929. He used this material, together with a more in-depth sample of 1229 of those patients to examine, inter alia, the routes by which patients came to be in the asylum, their social background and the behaviour indicating their insanity. While not outlining his sampling process, one of his key findings was that most common petitioners, that is any person willing to declare someone insane, were relatives $(57 \%)$, followed by doctors $(21 \%)$ and police $(8 \%)$. The latter, in particular, were more likely to target single foreign-born men who had recently arrived in the country. ${ }^{8}$ Fox's more in-depth study of 1229 cases, however, revealed that foreign-born people were not over-represented among those committed to asylums and that three-quarters of patients were from lower occupational levels. ${ }^{9}$

Several other key works similarly incorporate issues of migration, ethnicity and madness. ${ }^{10}$ Importantly, however, scholars turned increasingly to the many diverse records of psychiatric institutions. Stephen Garton's work on insanity in New South Wales, Australia, for instance, utilised admission registers, case papers, casebooks, and medical journals. He chose three hospitals in New South Wales and undertook random sampling to extract information relating to one quarter of the asylum population every third year for the period 1880 to 1939 . This generated a sample population of 3178. Among his findings were the over-representation of Irish Catholics (one quarter of all admissions in the 1880s) and the lax immigration laws of New South Wales compared with other places. ${ }^{11}$

The most recent ambitious statistical undertaking is that of Joseph Melling and Bill Forsythe who focused on the records of the Devon County Asylum at Exminster in England together with the borough asylums of Plymouth and Exeter and the fee-paying Wonford House. Using casebooks together with admission registers and committal records they established a database for a large sample of 4000 patients from a total of more than 13000 admitted to Exminster between 1845 and 1914 with smaller numbers for the other asylums. While they do not specify their sampling technique, their data was used to analyse a range of themes including diagnosis, admission and discharge. Among their key findings

\footnotetext{
7 Örnulv Ödegaard, 'Emigration and Insanity: A Study of Mental Disease among the Norwegian-born Population in Minnesota', Acta Psychiatrica et Neurologica Supplementum, 7, 4 (1932), 50-2, 54, 57, 82.

${ }^{8}$ Richard W. Fox, So Far Disordered in Mind: Insanity in California, 1870-1930 (Berkeley, CA: University of California Press, 1978), 80, 84, 87.

${ }^{9}$ Ibid., 105, 112.

${ }^{10}$ For summaries of this issue and relevant literature, see Angela McCarthy, introduction in Migration, Ethnicity and Madness: New Zealand, 1860-1910 (Liverpool: Liverpool University Press, 2015); and Angela McCarthy and Catherine Coleborne (eds), Migration, Ethnicity, and Mental Health: International Perspectives, 1840-2010 (London and New York: Routledge, 2012).

${ }^{11}$ Stephen Garton, Medicine and Madness: A Social History of Insanity in New South Wales, 1880-1940 (Kensington, NSW: New South Wales University Press, 1988), 6, 102, 104.
} 
were variations in diagnoses for male and female insanity and the greater likelihood that women would be discharged and that married individuals would be readmitted. ${ }^{12} \mathrm{~A}$ further key benefit of Melling and Forsythe's study is the extraction of data for all patients admitted to Exminster between 1880 and 1882 and the subsequent attempts to trace them in the 1881 Census. This record linkage methodology had been used profitably by other scholars before, and enabled Melling and Forsythe to consider findings about migration and household. ${ }^{13}$ They found that most patients were single but did not reside alone, that distant parishes were less likely to send patients to the asylum, and that migrants were also fewer among those admitted. ${ }^{14}$

Historical studies of madness using large statistical datasets were part of a wider mass quantification phase characterising social history in the 1970s. This phase has been important in reconstructing the pasts of mass numbers of people, and as such can be regarded as vital to uncovering and interpreting histories of mental illness over time. Such approaches, however, came under fire with the advent of the cultural turn with its focus on culture and language, interpretation rather than causation. Statistics, so critics argue, tend to dehumanise individual people and fail to deal with change over time. To counter such charges, students of madness turned to focus more fully on the 'form' of the patient clinical case, and also on patient experiences, though it is important to note that each of the statistical approaches discussed above were supplemented by recourse to more qualitative data to illuminate these experiences of inmates and the institutional worlds they inhabited.

\section{Qualitative Approaches}

Together with a new focus on quantifying data sources from the 1960s and 1970s, social historical approaches to the histories of health and medicine also paid new attention to accounts of illness, found in oral and written sources such as folklore, diaries and personal testimonies. Roy Porter's writings about 'medicine from below' placed more emphasis on the value of such sources of evidence about health and illness among not just the literate elite, but also the poor. Read in the context of a burgeoning cultural history of social life in the British and European contexts, Porter's work could be said to have stimulated a whole generation of inquiry into the language describing illness and medical practice. ${ }^{15}$ Porter also wrote about the social histories of madness, and a range of studies of the 'voices' of the mad and collections of the written narratives from the world's Anglo-American asylums generated significant interest in the idea of the 'patient's story'. ${ }^{16}$

Yet it was the growing interest in the institution of the nineteenth century and its volume of patient case records that has received the most sustained attention, as we suggest above. Nineteenth-century institutions were still 'present' in the landscapes of British and American towns and cities as historians ventured to write about their pasts. The move towards gradual institutional closures in a new age of community care created more urgency about telling the stories of past lives inside institutional settings, the worlds

12 Joseph Melling and Bill Forsythe, The Politics of Madness: The State, Insanity and Society in England, 1845 1914 (London and New York: Routledge, 2006), 66, 72.

13 See, for instance, David Wright, Mental Disability in Victorian England: The Earlswood Asylum, 1847-1901 (Oxford: Clarendon Press, 2001).

14 Melling and Forsythe, op. cit. (note 12), 84, 91, 80, 82.

15 Roy Porter, 'The Patient's View: Doing Medical History from Below', Theory and Society, 14 (1985), 175-98.

16 Roy Porter, A Social History of Madness: The World through the Eyes of the Insane (London: George Weidenfeld and Nicholson, 1987); Mary Elene Wood, The Writing on the Wall: Women's Autobiography and the Asylum (Urbana, IL: University of Illinois Press, 1994); Jeffrey L. Geller and Maxine Harris (eds), Women of the Asylum: Voices from Behind the Walls, 1840-1945 (New York: Anchor, 1995). 
of the wards, kitchens and gardens, and institutional regimes of power and medical knowledge. Attentive to these themes, historians started to examine patient case records as potential narratives of asylum life, treatment and possible recovery with greater intensity. Asylum patient case data could, historians argued, tell us more than clinical details about confinement and patients' diagnoses. This source material has been examined as evidence of patients and their institutional work, gender relations inside institutional spaces, class, diagnostic categories, practices of care and control, ethnicity and 'race' as case book designations, and as defining patient populations, and disability and bodies in the patient records. ${ }^{17}$

Interpreting the clinical cases as 'narratives' which produced specific outcomes for patients, and the very meanings of 'madness', is another important aspect of this type of qualitative analysis. ${ }^{18}$ Akihito Suzuki's account of the patient cases kept by Dr Hood at the Bethlem Hospital in the early nineteenth century reminded historians of the value in examining the literary qualities of cases and their framing of what Suzuki terms 'psychiatric subjectivity'. ${ }^{19}$ Catharine Coleborne's use of the idea of the clinical case as a narrative of a 'shifting subject' which produced gendered categories and identities for patients was influenced by the cultural histories of medicine in the North American tradition: John Harley Warner's concern with the clinical case as a textual artefact stimulated writing about the clinical encounter, as well as the role of doctors in creating the language of illness. Coleborne's subsequent work about families and insanity built on these traditions of scholarship that sought to examine a dialogue between patients, doctors and families in the clinical encounter. ${ }^{20}$

The circulation of medical knowledge globally has started to inform studies of psychiatry and institutional histories inside a much larger world of the mobility of not only migrants to the colonies, but also medical knowledge and personnel. Models for institutional practices existed, were modified and took new forms in colonial settings and legal jurisdictions, but were also populated by those who were trained in the imperial 'centres' in this 'age of mobility' around empire. The diffuse 'knowing' of peoples and categorising of medical populations took place around the empire through different imperial lenses, in this case, a British world lens. ${ }^{21}$ Sally Swartz, for instance, has provided a useful 'British world' framework for understanding the administration of colonial institutions and their origins in the $1860 \mathrm{~s}^{22}$ Leonard Smith's study of institutions in

17 Geoffrey Reaume, Remembrance of Patients Past: Patient Life at the Toronto Hospital for the Insane, 1870 1940 (Don Mills, ON: Oxford University Press, 2000); Bronwyn Labrum, 'The boundaries of femininity: madness and gender in New Zealand, 1870-1910', in Wendy Chan, Dorothy E. Chunn and Robert Menzies (eds), Women, Madness and the Law: A Feminist Reader (London, Portland, OR, and Coogee, NSW: Glasshouse Press, 2005), 59-77; Mills, op. cit. (note 1); Roy Porter and David Wright (eds), The Confinement of the Insane: International Perspectives, 1800-1965 (Cambridge and New York: Cambridge University Press, 2003); Angela McCarthy, 'Ethnicity, Migration, and the Lunatic Asylum in Early Twentieth-Century Auckland, New Zealand', Social History of Medicine, 21, 1 (2008), 47-65.

18 Catharine Coleborne, Reading Madness: Gender and Difference in the Colonial Asylum in Victoria, Australia, 1848-1888 (Perth, WA: API Network/Curtin University Press, 2007), 57-79.

${ }^{19}$ Akihito Suzuki, 'Framing psychiatric subjectivity: doctor, patient and record-keeping at Bethlem in the nineteenth century', in Joseph Melling and Bill Forsythe (eds), Insanity, Institutions and Society: A Social History of Madness in Comparative Perspective (London and New York: Routledge, 1999), 115-36.

${ }^{20}$ Coleborne, Reading Madness, op. cit. (note 18); Nancy Theriot, 'Negotiating Illness: Doctors, Patients and Families in the Nineteenth Century', Journal of the History of the Behavioural Sciences, 37, 4 (2001), 34-68; Coleborne, Madness in the Family, op. cit. (note 1).

${ }^{21}$ Maree O'Connor, 'Mobilizing Clouston in the Colonies? General Paralysis of the Insane at the Auckland Mental Hospital, 1868-99', History of Psychiatry, 26, 1 (2015), 69-79.

22 Sally Swartz, 'The Regulation of British Colonial Lunatic Asylums and the Origins of Colonial Psychiatry, 
the British Caribbean also sets out the British imperial context for asylums around the empire. ${ }^{23}$ Smith describes the 'empire of asylums', including those in Australia and New Zealand. Both scholars build on existing literature which defines colonial and imperial psychiatry. ${ }^{24}$ Smith's book pieces together the patchy patient records from the archives of several institutional sites in the British Caribbean. While neither author uses large data sets, these models support our multi-sited approach to archival research across the project, and are suggestive of the broad research methodology required to understand the issue of the populations of asylums in the imperial world, including record linkage.

Despite their proximity and shared histories, general historical studies bringing the colonial histories of New Zealand and Victoria, Australia, into one narrative are few in number. Yet both were colonies which had diverse European populations of migrants, including gold seekers, and also histories of frontier contact and conflict between settlers and indigenous peoples. ${ }^{25}$ The histories of insanity and confinement in the British colonial world context cited in this article have all expanded on these approaches. In the mixed populations of colonised peoples and new arrivals, the production of categories among the institutionalised took on new forms, and arguably both reproduced and refashioned social categories produced 'at home' in the British and Irish context, meaning that these institutions in the colonies should be interpreted inside a set of understandings of the British imperial world. Laws and processes of empire were mobile, as were the medical and legal personnel whose careers helped to establish the colonial asylum systems of which the institutions were part. Historians, therefore, have layered their readings of the case book sources, seeing them as part of these medical and legal inheritances, and also situating them within a critical analysis of colonialism and its specific power relations. ${ }^{26}$

\section{The Data: Benefits and Limitations}

It is within these broad historical and historiographical contexts that our research is situated. We elected to merge both quantitative and qualitative approaches to examine key issues relating to three asylums in New Zealand and one in Australia between the years 1864 and 1910. The New Zealand asylums were: the Auckland Asylum in the North Island of New Zealand (whose records we consulted from 1870); the Dunedin and Seacliff asylums, located in Dunedin in the South Island of New Zealand (from 1864); and Ashburn Hall, a private asylum also in Dunedin (from 1882). Australian data from 1870 was collated from the Yarra Bend Asylum in Melbourne, Victoria. Our first objective was to create four patient datasets based on information extracted from the patient casebooks for each institution and entered into a Microsoft relational database. Given the sheer number of patients and volume of data, we elected to extract information for those admitted to the four asylums every third year, for example, 1864, 1867, 1870 and so on. Collectively these institutions yielded records for approximately 4000 patients who were admitted to these

\footnotetext{
1860-1864', History of Psychology, 13, 2 (2010), 160-77.

${ }^{23}$ Smith, op. cit. (note 1), 12-19.

${ }^{24}$ See, for example, Shula Marks, 'What is Colonial about Colonial Medicine? And What has Happened to Imperialism and Health?', Social History of Medicine, 10, 2 (1997), 205-19; Warwick Anderson, 'Postcolonial histories of medicine', in Frank Huisman and John Harley Warner (eds), Locating Medical History: The Stories and Their Meanings (Baltimore, MD, and London: Johns Hopkins University Press, 2004), 285-306.

${ }^{25}$ For more examples of this transcolonial context, see Coleborne, Madness in the Family, op. cit. (note 1); Rollo Arnold, 'The Australasian peoples and their world, 1888-1915', in Keith Sinclair (ed.), Tasman Relations: New Zealand and Australia, 1788-1988 (Auckland: Auckland University Press, 1987), 52-70.

${ }^{26}$ Catharine Coleborne, Insanity, Identity and Empire: Insanity and Institutional Confinement in Australia and New Zealand, 1873-1910 (Manchester: Manchester University Press, 2015).
} 
facilities between 1864 and 1910. The details entered into this database included basic demographic information such as name, age, marital status, occupation, religion, address, date of admission to the asylum, previous attacks, duration of the existing attack, presumed cause of insanity, and name and address of relatives.

Further information for the database was also gleaned from these case notes - at the time of admission and over the course of the patient's stay - to reflect the specific areas of research interest to the team including migration pathways, previous admissions to an asylum (of both the patient and their family members), religious delusions, asylum transfers, gender, class and ethnic identities, and heredity and vice. ${ }^{27}$ Data gleaned from other sources for the Dunedin public asylum, including asylum admissions registers, committal forms, and questionnaires, together with immigration records and vital events registers supplemented this information. In the case of Auckland and Dunedin, casebooks for non-sample years were also consulted for details about migration and ethnicity, and some Auckland data was also tested against control samples of patient cases from other years. Data from the Yarra Bend Asylum was read against prior scholarly work focused on records from the same institution.

This multi-sited approach, including information about several thousand patients, presents both opportunities and potential pitfalls. Several limitations were common to both our qualitative and quantitative approaches.

First, as with asylums elsewhere in the world, legislation stipulated the maintenance of record keeping in asylums. Victoria's legislation, the Lunacy Statute of 1867, became a model for New Zealand's law of 1868. After that date, records were required to be kept and details of admissions taken down in a printed book which followed the same format, although Victoria's format was slightly different from that used in New Zealand institutions. For example, asylum doctors in New Zealand collated more information from family members under specific headings than was usual at the Yarra Bend. ${ }^{28}$ However, this record keeping was not uniformly undertaken around New Zealand. ${ }^{29}$ Divergence from regulations at Auckland in 1879, for instance, was noted with a new Register of Admissions 'not kept in manner required by Statute'. ${ }^{30}$ The casebooks that we consulted were similarly not standardised across all the asylums and they changed over time. ${ }^{31}$ Early casebooks, for instance, were often blank pages without template guidelines, though eventually a basic pro forma template emerged usually providing headings to specify a patient's sex, age, marital status, occupation, religion, residence, previous attacks, duration of existing attack, presumed cause of insanity, if suicidal or dangerous, and relative's name

\footnotetext{
${ }^{27}$ For further details, see Coleborne, Insanity, Identity and Empire, ibid.; Maree Dawson, 'National Fitness or Failure? Heredity, Vice and Racial Decline in New Zealand Psychiatry: A Case Study of the Auckland Mental Hospital, 1868-1899' (unpublished PhD thesis: University of Waikato, 2012); Elspeth Knewstubb, 'Respectability, Religion, and Psychiatry in New Zealand: A Case Study of Ashburn Hall, Dunedin, 1882-1910' (unpublished MA thesis: University of Otago, 2011); McCarthy, Migration, Ethnicity, and Madness, op. cit. (note $10)$.

28 On the differences between archival records across four colonial institutions, see Coleborne, Madness in the Family, op. cit. (note 1), 145-53.

29 This was also the case elsewhere in the world. See, for instance, Andrews, op. cit. (note 4), 260.

${ }^{30}$ Appendices to the Journals of the House of Representatives (hereafter AJHR), 1879, H-4, 6.

${ }^{31}$ David Wright also comments on the array of certification processes across institutional and national sites. See 'Getting out of the Asylum: Understanding the Confinement of the Insane in the Nineteenth Century', Social History of Medicine, 10, 1 (1997), 146-9.
} 
and address. ${ }^{32}$ Most casebooks, however, provided space for a summary to be taken from the completed medical certificates, two of which were required for a patient to be admitted to an asylum. A facing page allowed medical remarks, both at the time of admission and at subsequent periods, to be made. These medical notations often contained further biographical or social information about the patient, through to details of their bodily state and physical examinations. In this way the pro forma was perhaps more influential in the shaping of the information contained in the case records than contemporary medical trends and ideas. By the second half of the nineteenth century, most British and colonial institutions were part of a trend towards 'scientific' approaches to mental medicine. ${ }^{33}$ The casebook pro forma and reporting was part of this larger trend.

A second limitation concerned the recording of information by asylum doctors and attendants. What Jonathan Andrews calls the 'incompleteness and inter-textual discrepancies' in the Scottish context was amplified in the colonial institutions in relation to the concern that colonial families were highly fragmented. ${ }^{34}$ It is notable, for instance, that data extracted from these records was not consistently available across all the institutions, as some asylums provided more extensive descriptions than others. For some patients, notes on their stay in the asylum extended to other pages of the same or subsequent casebooks. Even within each casebook the range of information on individual patients is far from standard. Patients who were transferred in large groups from other asylums tended to have minimal information attached to their cases. Some institutions noted clearly the patient's diagnosis in either the admission register or the case book, but other facilities failed to do so. This meant that certain comparative questions across all asylums, such as whether particular ethnicities were more likely than others to be equated with a specific 'disease', could not be addressed. ${ }^{35}$ There were also differences in the diagnostic terminology used between the asylums, further complicating any comparative analysis of medical trends and ideas between the asylums. The systematic extraction of information was likewise hindered by the problem of missing casebooks. For the public asylum at Dunedin, for instance, the earliest extant casebooks include a large unwieldy continuation tome which lists those patients still in the asylum several years after their admission. Patients who had entered the asylum in earlier years and were then either discharged or died are absent. This particular tome also replicates much of the material found in another casebook so the database only includes those patients who did not appear in the original continuation volume. Such problems were rectified to some degree by recourse to other sources including admission registers, death and discharge registers, patient questionnaires and so on. These helped flesh out missing information in the casebooks.

A third pitfall was to ensure that we did not incorrectly equate our information with 'evidence' of an insight into the lives of all patients. As Swartz, writing about South African institutions, observes, surviving records from some institutions are very scantily

\footnotetext{
32 Interestingly, there was no formal legal requirement for casebooks to be maintained in Scottish asylums, the requirement instead being an admission book. For asylums that did keep casebooks, printed forms were generally introduced after 1800. For instance, a pro forma was only introduced in Edinburgh in 1874, Woodilee in 1900, and Gartnavel in the 1920s. See Gayle Davis, 'The Cruel Madness of Love': Sex, Syphilis and Psychiatry in Scotland, 1880-1930 (Amsterdam and New York: Rodopi, 2008), 24-5.

33 Andrews, op. cit. (note 4), 260.

${ }^{34}$ Ibid., 262.

35 This was an area of interest for Roland Littlewood and Maurice Lipsedge, Aliens and Alienists: Ethnic Minorities and Psychiatry (London: Unwin Hyman, 1989).
} 
fleshed out, while others are full of information, making the records uneven as a body of data for historians to use. ${ }^{36}$ It is possible, even likely, that those patients with a more interesting or unique diagnosis or history had a longer and more detailed written record than those patients who had more common backgrounds or diagnoses. Patients who were unable to speak at all or who had no one to speak for them often left very scant case records, resulting in minimal representation in both quantitative and qualitative analysis of the records. Patients unable to speak English could be similarly passed over in the records and in subsequent analysis. There is also the question of the reliability of evidence gained from patients and family and friends.

Fourth, we encountered issues directly related to the database, including how to handle repeat admissions. We elected to include only the first admission from the sample years in the databases. This meant that the patient may have been admitted in earlier years that were not part of the database sample years. In such cases, we noted in the database whether the patient had previously been admitted and confined again at a later date. This, of course, was dependent on the information contained in the relevant case note indicating that the patient had been committed in other years. Additionally, we must always be conscious that our database sample is exactly that: a sample and does not give a complete summary of admissions to these asylums. And, of course, there are arguments that aggregate statistics reveal little about the lives and experiences of people with mental illness, hence our focus also on qualitative perspectives. Yet such biases are also evident in qualitative approaches to the sources. The notes that doctors entered in the patient casebooks, for instance, provide insight into their judgements, which were medically, morally, religiously and culturally informed. ${ }^{37}$

Fifth, this article has been arguing for the value of access to patient case records for the purpose of narrating the past of both the histories of mental health and well-being, but also so that historians might further engage with ideas about access to a large cache of historical, archival data to enable collaborative historical projects. The use of historical records involves historians navigating questions of ethics - access to archival collections, the use of sensitive materials and ideas about restriction. Most sensitive medical records are not available to researchers or the general public without specific permission. In the case of most past psychiatric records held in state public archives, access is permitted so long as the records are more than seventy and in other cases one hundred years old. ${ }^{38}$

Debates about historians' access to records such as the ones used in this article have focused on a range of issues, including the role and relevance of records in creating social histories of illness, welfare, crime and institutions in the past. As the writer of a landmark text in the history of Australian 'medicine and madness', Stephen Garton, has suggested, access to records allows historians to paint a broader picture of a world now long forgotten. ${ }^{39}$

Another aspect of the use of these records is their continued life after the end of a finite research project. Researchers who gain access to records in some contexts - such

\footnotetext{
${ }^{36}$ Swartz, 'Colonial Lunatic Asylum Archives', op. cit. (note 2), 291.

${ }^{37}$ Knewstubb, op. cit. (note 27).

${ }^{38}$ For some international examples of restrictions surrounding access to patient records, see David Wright and Renée Saucier, 'Madness in the Archives: Anonymity, Ethics, and Mental Health History Research', Journal of the Canadian Historical Association, 23, 2 (2012), 68-70.

${ }^{39}$ Stephen Garton, 'Shut off from the Source: A National Obsession with Privacy Has Led to Fears for the Future of Australian Social History', The Australian, Higher Education Supplement, 22 November 2000, reproduced at: www.asap.unimelb.edu.au/asa//aus-archivists/msg00470.html (last accessed 3 December 2015).
} 
as using records following a specific application to a relevant authority, for a discrete research project - should not expect to use these records in perpetuity. The records used in this study do not fall into that category - most were accessible to us as researchers under the rules of public access, and no special requirements regarding their use (except for the removal of patient surnames for the Dunedin data, and permission to reproduce images from all of the patient records in any publication) were prescribed. This is because the records we used from public institutions are available under the rules of access to records created more than seventy years earlier. There is an argument to be made for the ways that histories such as those created in our project provide potential for researchers, including genealogists, to continue to locate lost family members, and to continue to understand their past family histories of mental illness conditions, or migration stories. Speaking to genealogical researchers and to members of the public about this field of research can have surprising results, such as a thirst for more knowledge about past institutional confinement practices, a veritable opening up of the closed worlds of the psychiatric wards that may hold answers to family puzzles and secrets. ${ }^{40}$ At the same time, we must also be aware of the sensitivity of such data for family members who may not wish such information to come to light. ${ }^{41}$ Although recognising this, many names of patients are in the public domain - in police gazettes, in colonial newspapers, and so on. This article refers only to initials of surnames, and yet the archives are open to anyone able to access these to examine their contents, and our references provide a clear trail to identity.

Despite these potential problems, there are benefits to be gleaned from the sources and the methods that we adopted. Beginning with the quantitative approach, the large number of patient cases explored in this project lends statistical credibility to conclusions drawn about the patient populations at individual asylums and across the four sites. Moreover, it enabled us to undertake comparisons over time, particularly in relation to the social characteristics of patients. We took care where possible to assess such transformations by decade given that aggregate statistics disguise diversity over time. Yet the length of time over which these patient cases were drawn reduced the extent to which significant features evident in statistical analysis may be written off as simply being due to the vagaries of a specific point in time. Our database also facilitated statistical analysis of such issues as the prevalence of hereditary insanity, the proportion of family admitted to colonial rather than 'homeland' asylums, migration pathways, asylum transfers, the length of time that had elapsed between arrival in the colony and admission to an asylum, sex ratios, and the presence or absence of family networks. These all buttressed our connected qualitative engagement with these themes.

Clearly the multiple site, long-term nature of the data collected as part of the methodology used in this study, and the subsequent creation of a wide-ranging patient database is well suited to quantitative data analysis. However, these records - often extremely rich and in many instances based on the subjective thoughts of doctors and asylum personnel, as well as more 'clinical' details and insights - present great opportunities for historical enquiry of a more qualitative nature. For example, the sheer number of patient case records and the ideas expressed within them allows historians to trace developments and changes in medical ideas at the 'coalface' of asylum medicine, and

\footnotetext{
${ }^{40}$ See for example Catharine Coleborne, 'Reading Insanity's Archive: Reflections from Four Archival Sites', Provenance, 9 (September 2010), 29-41, http://prov.vic.gov.au/explore-collection/provenance-journal/provenan ce-2010/reading-insanitys-archive (last accessed 5 May 2017).

${ }^{41}$ See Wright and Saucier, op. cit. (note 38), 73-76, for further discussion about these ethical issues.
} 
to contrast these ideas between various psychiatric institutions. Such observations must be treated with caution and should not necessarily be accepted as indicative of asylum practices across New Zealand, the Australasian colonies or the British world. But these patient records consulted in this study are a solid starting point for analysis of trends in asylum practices across these various settings.

The length of time these records span allows historians to take a longitudinal approach to studies of asylum populations and of medical practices, particularly changes in ideas about psychiatric medicine over the late nineteenth and the early twentieth century. However, while changes in the demography of asylum populations can be traced fairly easily, particularly through the use of the patient database compiled for this study, identifying and drawing conclusions about medical practices and ideas requires a far more nuanced and sensitive approach. Such changes may be obscured in the case notes due to shortcomings in the records themselves.

To counteract this, we turned to other sources to examine the circulation of medical knowledge. This was explored primarily through analysis of records in the form of medical publications, particularly the British Medical Journal. In an international context, medical journals were critical to the transnational transfer of theories about different diagnoses, and diagnostic definitions were often deployed in New Zealand and elsewhere. ${ }^{42}$ Analysis of this transfer through medical journals focused particularly on patient case notes from the Auckland Mental Hospital, and the ways that theories and terminology were shared between medical journals and case notes. This is particularly evident when exploring texts relating to specific diagnoses. The British Medical Journal published a large number of articles in the latter stages of the nineteenth century about congenital idiocy or Down's Syndrome. These articles often referred to concerns about a patient's head and face shape, while during a similar period patient case notes from the Auckland Mental Hospital described a patient admitted to the institution under the diagnosis of congenital idiocy as 'imbecile with all the typical characteristics', including 'a very small cranium, quite out of proportion to the facial part of the skull' ${ }^{43}$ But as well as signs or symptoms of conditions being shared between medical journal and antipodean asylum, the causes of conditions were also discussed in similar terms between the written, published medical journal record and the documented information left by doctors working at the Auckland Mental Hospital. Another example of these shared ideas was heredity. Heredity was identified as the most significant factor in congenital idiocy cases by G.W. Grabham in the British Medical Journal, while congenital idiocy cases from the Auckland Mental Hospital frequently cited a hereditary taint as a cause of this condition, in admitted patients. ${ }^{44}$ Concerns about the formation of families through consanguineous marriage also permeated Auckland Mental Hospital case notes and medical journals, as the case note for one congenital idiocy patient observed that her parents were cousins. ${ }^{45}$ Articles in the British Medical Journal mentioned the role of such relationships in congenital idiocy cases, referring to 'defective children, the offspring of neurotic cousins' ${ }^{46}$

\footnotetext{
42 Maree Dawson, 'A degenerate residuum? The migration of medical personnel and medical ideas about congenital idiocy, heredity, and racial degeneracy between Britain and the Auckland Mental Hospital, c.1870 1900', in McCarthy and Coleborne (eds), op. cit. (note 10), 93.

43 Archives New Zealand, Auckland Regional Office (hereafter ANZ ARO), YCAA, 1048/5, folio 751.

${ }^{44}$ G. W. Grabham, 'Remarks on the Origin, Varieties and Termination of Idiocy', British Medical Journal (16 January 1875), 73, cited in Dawson, 'A degenerate residuum?', op. cit. (note 42), 100.

${ }^{45}$ ANZ ARO, YCAA, 1048/6, folio 221.

${ }^{46}$ G. E. Shuttleworth, 'Discussions on the Prevention of Insanity, Part III', British Medical Journal (1894), 521.
} 
Meanwhile, a comparative approach enabled us to compare and contrast colonial records with those in Britain and Ireland. Interestingly, at Ashburn Hall the case book templates from 1900 resemble those of the James Murray Royal Asylum where Frank Hay, superintendent at Ashburn, had previously worked. This meant that the notes were generally more complete with regard to a patient's physical condition and family and personal history than the notes from his predecessors' years of managing the asylum. Yet although the pro forma Hay introduced contained similar categories to that at James Murray's Asylum, it was set out in a slightly different manner, with information about family and personal history being recorded before information about physical condition. It also contained a category for recording a family tree, which was not introduced at James Murray until 1902, when their pro forma changed slightly. The detailed categories of the James Murray's and Hay's pro forma books reflect the increasing emphasis during the last decades of the nineteenth century on more 'scientific' approaches to mental medicine, which saw important changes being recommended for asylum case notes in England and Scotland. ${ }^{47}$

We turn now to highlight two particular avenues in which our research may benefit other scholars: categories of data analysis; and record linkage.

\section{Analysing Categories in Patient Records}

Ian Hacking called the statistical production of the nineteenth century a process of 'making up people', and argued that people came 'to fit their categories'. In addition, and as our own study shows, Hacking suggested that social change created 'new categories of people'. ${ }^{48}$ The rapid changes taking place in colonial societies as a result of settlement and immigration patterns determined that ideas about belonging, 'race' and ethnic identification, gender and class status would shape the ways that colonial populations managed their social institutions.

Hacking was one of those scholars critical of the vast production of statistics which captured people inside specific rubrics and ways of knowing, a process of state making that defined the nineteenth-century world. Our project's attention to the analysis of our patient case data has taken different forms: the quantification of our sampled data; the qualitative analysis of the institutional worlds; a focus on rich themes such as illness diagnoses, religious affiliation, gender, ethnicity and migration; and other aspects of the patient population. More specifically, two of the institutions, the Yarra Bend Asylum and the Auckland asylum, became the focus of a study of identity and insanity in the colonial and imperial world context. In this section, we discuss the ways that breaking down the large data collection into specific categories assists historians to analyse it meaningfully, while, at the same time, reproducing the tendency for institutions to categorise and label inmates. This paradox is worth examining as an aspect of the ongoing tensions between using patient case records as a form for their content, as well as for their production of ideas about insanity and populations of the insane.

Diagnostic categories presented specific challenges of interpretation. Record keepers used a variety of terms for what might have been commonly understood as the same affliction among those people admitted to the institutions. There were subtle changes over

\footnotetext{
${ }^{47}$ Knewstubb, op. cit. (note 27), 36-9.

${ }^{48}$ Ian Hacking, 'Making up people', in Thomas C. Heller, Morton Sosna and David E. Wellbery (eds), Reconstructing Individualism: Autonomy, Individuality, and the Self in Western Thought (Stanford, CA: Stanford University Press, 1986), 223.
} 
time, and some of these are clearer than others. Our other concern with the data entry into the team's databases was the fact that 'causes' of mental illness as ascribed and identified at the time of committal could both contradict or overlap with 'diagnoses' that were recorded. A certain amount of guesswork was involved in managing these aspects, and the safest approach seemed to be to keep causes and diagnoses separate, but to render the diagnosis in discussion about cases in ways which drew upon the surrounding discussion about an inmate's illness. Examples from Auckland include discussions of puerperal insanity and general paralysis of the insane (GPI), both of which tended to be accompanied by collections of symptoms, wider contexts of understanding and commentary.

Analysis of patient case notes from the Auckland asylum showed that the condition of puerperal insanity was attributed to causes linked to childbirth, breast feeding and general deprivation. Between 1868 and 1899, eighty-three women were admitted to the Auckland asylum under this seemingly self-explanatory diagnosis. ${ }^{49}$ However, a more comprehensive and patient-focused interpretation of this condition needs to be rooted in the social context of the time. The contemporary concept of respectability is essential to locating this diagnosis in its wider context. This is demonstrated through the case note of Elizabeth W, admitted to the Auckland asylum in 1872 and described in her case notes as a 'young and respectable 25 year old settler's wife' ${ }^{50}$ The idea of the patient as respectable is reinforced by her marital status and the implication of childbirth within the bounds of marriage. Another patient admitted to the Auckland asylum with a puerperal insanity diagnosis was Elizabeth $\mathrm{P}$, whose case note shows that she 'talks incessantly, shouts, swears, is abusive' and 'will not have the child near her' when suffering from puerperal insanity. ${ }^{51}$ This was contrasted to her previous behaviour, which was said to be 'good tempered, affectionate, very industrious. ${ }^{52}$ This 'respectability' and its role in the social construction of puerperal insanity is particularly evident when these puerperal insanity case notes are contrasted with those of some other patients. For instance, Lucy A was admitted to the Auckland asylum in 1885 under the diagnosis of epilepsy and is described in her case notes two years after her admission as "quarrelsome, uses obscene language and so violent that it is necessary to seclude her for a day or two'. ${ }^{53}$ Unlike Elizabeth P, Lucy A's prior behaviour was not noted. Similarly, Eliza L, admitted due to 'intemperance' was described as 'excessively gross and filthy' in habits and having 'lost all sense of shame', yet there was no reference to previous behaviour to contrast this disordered behaviour with. $^{54}$

General paralysis of the insane (GPI) had a much more variable and subjective aetiology than puerperal insanity. Theories about the causes of GPI changed with location and time, shifting from a theory of overwork to sexual excess and syphilis. This is demonstrated by an examination of the case notes of patients admitted to the Auckland asylum with GPI, over a period of three decades and is illustrated in the table below:

In this table, 'vice' refers to non-reproductive sexual activity or non-marital sexual activity, and substance and alcohol abuse. Heredity refers to a family history of mental illness. 'Both' refers to patients who either have a family history of mental illness and have

\footnotetext{
${ }^{49}$ Dawson, 'National Fitness or Failure?', op. cit. (note 27), 206, 210.

50 ANZ ARO, YCAA 1048/2, folio 91.

51 Ibid.

52 ANZ ARO, YCAA 1048/7, folio 207.

53 ANZ ARO, YCAA 1048/4, folio 29.

54 ANZ ARO, YCAA 1048/5, folio 571.
} 


\begin{tabular}{lcccccc}
\hline Year & Total & $\begin{array}{c}\text { Heredity as } \\
\text { a cause }\end{array}$ & $\begin{array}{c}\text { Vice as } \\
\text { a cause }\end{array}$ & $\begin{array}{c}\text { Heredity } \\
\text { and vice }\end{array}$ & No Cause & Other Cause \\
$1870-79$ & 16 & 0 & 2 & 0 & 12 & 2 \\
$1880-89$ & 15 & 1 & 0 & 0 & 12 & 2 \\
$1890-99$ & 33 & 2 & 17 & 1 & 9 & 4
\end{tabular}

Source: Archives New Zealand Auckland Regional Office, YCAA patient case books 1048/1, 1048/2, 1048/3, 1048/4, 1048/5, 1048/6, 1048/7, 1048/8, YCAA patient admissions registers 1021/1, 1021/21021/3.

Table 1: Patients admitted to Auckland Lunatic Asylum with GPI, 1870-99.

themselves indulged in vice, or whose family history includes individuals who yielded to vice. ${ }^{55}$ This table shows that the proportion of GPI patients whose condition was attributed to vice increased dramatically in the last decade of the nineteenth century, compared to the previous two decades. Justifications for this change can only be speculative, but an examination of contemporary medical texts from other countries, particularly Great Britain, mirrors this trend.

Diagnoses and diagnostic categories formed a component of the data analysis, and these aspects are especially important to the medical historical knowledge created by the collection of the patient records. As the two previous examples show, other ways of analysing the patient records, such as using concepts of gender, age and class, offer different insights into the illnesses, their sufferers and the social worlds from which they came into the institutions.

To examine the question of identity formation, both in the sense of inmate identifications and of the labels that were applied to institutional inmates, other categories of data analysis became central planks of the wider project. Given the scholarly preoccupation with gender and insanity, new ways of seeing gender in formation inside the patient records, as much as inside the spaces of the institutions, are critical. The use of intersectional analysis - seeing gender and ethnicity in relation to each other - offers new insights about the institutional population. Men and women inside the institutions were mostly European. The focus of attention was on the weakness of the diverse European 'races' as migrants arrived and displayed mental breakdown or family histories of mental weakness. ${ }^{56}$ Official reporting about institutional populations continued to reinforce this concern, which played out in the patient casebooks and their descriptions of insanity among white men and women, as we show below.

Interpreting the gendered nature of the colonial institutional patient population has been one of the major aspects of recent historiographical debate. ${ }^{57}$ Single men, it is argued, were more likely to dominate the colonial populations of the mad until the twentieth century. ${ }^{58}$ Of the 1747 men in the Yarra Bend sample, 547 were married and 931 were single, reinforcing the idea that in this period, single men were slightly more likely to be confined than married men. At Auckland the cases reveal a similar pattern in the sample, with more single men than women confined, though not such a large difference between men and women. Overall, single men represent 31 per cent of the total sample of patients,

\footnotetext{
55 Dawson, 'National Fitness or Failure?', op. cit. (note 27), 186.

56 Catharine Coleborne, 'White Men and Weak Masculinity: Men in the Public Asylums in Victoria and New Zealand, 1860s-1900s', History of Psychiatry, 25, 4 (2014), 468-76.

${ }^{57}$ Ibid., 469-70.

${ }^{58}$ Garton, op. cit. (note 11), 118-31.
} 
as opposed to 15 per cent of women. The total number of 1115 married patients over this period, where this information was known, includes roughly equal numbers of men and women, meaning that married men and married women both constitute 18 per cent of the total of sampled patients. More men than women in the Yarra Bend group - sixty-two as opposed to fifteen - presented cases with missing information as to their marital status, suggesting that the social connections provided by wives and families, or other social contacts, were possibly important also to the gathering of personal details for men. Widows and widowers comprise another group of patients, with double the number of widowed women at the Yarra Bend. The ages, too, of institutionalised people followed the pattern expected by authorities: most inmates were in the middle stages of life when organic disease, and social pressures, tended to take their toll; older members of the population became more vulnerable to illness, dementia and brain disease and diseases caused by poverty and destitution.

Class differences are only partly discernible in occupational categories collected by institutions, but they also played a role in producing certain theories about insanity in colonial worlds. Occupational categories including 'labourer' and 'domestic servant' were obviously gendered. In both examples, contemporaries held beliefs about the impact of a lonely life upon single, peripatetic male labourers or miners who were often found insane in more remote areas of colonial places and brought to the colonial metropolitan institutions; or similarly, about the situations of many women working in domestic service who were brought to the asylum by employers or older men, their stories viewed and narrated through the prism of nineteenth-century institutional ideas about gender and femininity.

Taking just one example, domestic service was known to be a salient feature of the English class structure in the nineteenth century. ${ }^{59}$ During the nineteenth century and particularly in the period under investigation, from the 1870s onwards, huge numbers of women took their place among the journeyers crossing the oceans in search of new opportunities, and many of them were looking for work in the colonies as domestic servants. ${ }^{60}$ Many of these unmarried women became relatively independent in their search for new opportunities across the British world empire. ${ }^{61}$ They were sought after in Australia as domestic servants, being well-trained and superior, at least in the eyes of colonists and settlers who wished to employ good workers. ${ }^{62}$ However, this was changing over the period of 1870 to $1910 .^{63}$ Nonetheless, the number of women inside the institutions whose occupation was listed as domestic servant is evidence of their continued presence in the labour force, if not their relatively vulnerable status inside homes and households. ${ }^{64}$ This type of vulnerability and conflict could leave them more prone to mental distress. They also lived outside their own family situations, another constant concern of asylum doctors and administrators. ${ }^{65}$

${ }^{59}$ Liza Picard, Victorian London: The Life of a City 1840-1870 (New York: St Martin's Press, 2005), 120.

${ }^{60}$ Emma Robinson-Tomsett, Women, Travel and Identity: Journeys by Rail and Sea, 1870-1940 (Manchester and New York: Manchester University Press, 2013), 18-9.

61 Jan Gothard, Blue China: Single Female Migration to Colonial Australia (Melbourne: Melbourne University Press, 2001).

62 Beverley Kingston, My Wife, My Daughter, and Poor Mary Ann: Women and Work in Australia (Melbourne: Thomas Nelson, 1975), 30.

${ }^{63}$ Ibid., 48-9.

${ }^{64}$ See Penny Russell, A Wish of Distinction: Colonial Gentility and Femininity (Carlton, Vic.: Melbourne University Press, 1994), 170-1. On domestic servants with stories of fear and abuse by men, see Coleborne, Madness in the Family, op. cit. (note 1), 90.

65 See Coleborne, Madness in the Family, op. cit. (note 1), 52. 
Our data bears out some of the surrounding histories of class, occupation and domestic service for women. The majority of domestic servants admitted to the Yarra Bend asylum in the period were single women. Of the 269 women designated as domestic servants (or similar explicit label of paid domestic work outside the home) 170 were single, and 141 of these were aged between fifteen and forty-five. In their childbearing years, these women were likely to have experienced sexual contact with men outside marriage. The polite use of the term 'trouble', listed as a cause of insanity for one 40-year-old Catholic woman, Mary F, hid what appeared to be an awkward and unmentionable experience. ${ }^{66}$ Among the thirty-six women at the Auckland asylum who had been domestic servants before their institutional committal were twenty-two single women. Although pregnancy was not recorded in any of their cases, these women had suffered disappointment in love, and in at least one case, pregnancy. ${ }^{67}$

Doctors also categorised patients according to birthplace and tabulated statistics show the over-representation of Irish-born people in colonial institutions, a feature replicated elsewhere in the British world. ${ }^{68}$ Moreover, at the Dunedin and Seacliff asylums, especially, doctors were more inclined to comment on the 'race' and ethnicity of patients. This could occasionally encompass a broad comment referring to a patient's national, regional, and county origins. But it also entailed linking place of origin with biological characteristics. Of one patient it was said, 'A big broad loosely built slouchy German. Typical good humoured German features'. Such judgements reflected developments in science and anthropology from the 1860s which characterised different ethnicities with a particular emphasis on skin and hair colour, stature and physiognomy. The diverse accents and languages exhibited by patients also attracted comment and were frequently linked to a patient's behaviour. ${ }^{69}$ International comparison as to how certain ethnicities in asylums were depicted would be instructive.

Religion, too, played a role in how doctors categorised patients in colonial asylums. Asylum admissions registers often had a space to record patients' religious affiliations, for example Church of England, Catholic, Wesleyan, Presbyterian, Jewish, and even 'Freethinker' ${ }^{70}$ As with ethnicity, patient behaviours were at times characterised in doctors' notes by reference to their religion, particularly where this was different from the doctors' own religious beliefs. At Ashburn Hall, Jewish patients were categorised along both ethnic and religious lines, while there were indications that doctors expected a certain type of irrationality from Catholic patients. Hannah L was described as having 'Jewish features' ${ }^{71}$ In addition to commenting on her ethnicity, the superintendent Frank Hay also asked her what she thought of 'the guyem, [sic] Christian', and recorded her response, stating that she had given the conversation a 'jewish character' ${ }^{72}$ In the case notes for the epileptic Catholic patient Amy S. Hay recorded, 'There is no bible reading or epileptic religiosity (she is a Roman Catholic).' For other epileptics admitted to Ashburn, religiosity did not appear as a recorded symptom nor was its absence commented upon. It seems that

\footnotetext{
${ }^{66}$ Public Record Office Victoria, VPRS 7400/P1, unit 8, folio 78, 5 May 1885; VPRS 7400/P1, unit 13, folio 302, 17 February 1903.

${ }^{67}$ A larger number of women were listed as working in the home, home duties, household work and related terms, but this commentary is confined to those designated as servants.

${ }^{68}$ McCarthy, Migration, Ethnicity, and Madness, op. cit. (note 10), 77-78.

69 Ibid., ch. 6.

${ }^{70}$ See, for example, Ashburn Hall, Register of Admissions, 1882-1948, Hocken Collections, AG-447-5/01.

${ }^{71}$ Knewstubb, op. cit. (note 27), 64.

${ }^{72}$ Ibid., 65.
} 
Amy's Catholicism was assumed to render her more susceptible to insane religiosity. ${ }^{73}$ Such judgements and the pathologising of religion reflects in part the trend identified by medical historians that in the late nineteenth and early twentieth century medical practitioners were increasingly taking over the traditional clerical role as gatekeepers of morality and normality. ${ }^{74}$

Although they pathologised certain types of religion or religious expression, asylum doctors also recognised the potential benefits of religious worship in assisting recovery. Ninety-five per cent of all settlers in New Zealand identified as adherents of a Christian denomination at the end of the nineteenth century. ${ }^{75}$ Regular worship could form part of the therapy offered by asylums. By the 1880s all New Zealand asylums provided for Sunday services, although the Auckland asylum was the only one equipped with its own chapel. ${ }^{76}$ The Ashburn Hall doctors not only recorded the religious affiliations of their patients, but also commented on how and whether their patients, particularly the female ones, participated in religious worship. Proper and respectful adherence to religious rituals might be recorded as evidence of improvement in mental state, while 'bad' religious expression such as excessive bible reading or loud prayer or hymn singing at inappropriate times was treated as symptomatic of mental illness. ${ }^{77}$

This section has demonstrated the value of a large sample of data in the re-examination of specific themes in British world histories of institutional confinement, medical diagnoses, gender, class, occupation, ethnicity and religion among other themes. It has opened up a few areas of our evidence base to hint at the wider implications of research using institutional records across multiple sites, and especially shows the relevance of unpicking categories of data analysis in relation to each other, resituating and questioning the evidence as it highlights new aspects of what it meant to be 'mad' and unwell in the colonial setting and era, sometimes far from 'home'. The idea of labelling and ascribing identities in the institutions of the past both enabled our data collection, shaped it, and also gave us pause for thought about the contemporary meanings of such labels and their application. To further and more deeply interrogate some records in a large database, there is a need to constantly link to and seek out ancillary sources, which leads us to the vital theme of record linkage in the following section of this article.

\section{Record Linkage}

A further benefit of our study was to link patients to other records, a methodology undertaken by historians such as David Wright, Joseph Melling and Bill Forsyth. While these scholars were able to utilise the rich original census manuscripts in the UK to trace patients over time within and beyond the asylum, similar linkage for patients in the Dunedin public asylums was constrained due to the destruction in the 1970s of original New Zealand census manuscripts. Instead, these patients were imaginatively pursued through manual record linkage to other sources including immigration records,

73 Ibid., 66.

${ }^{74}$ See, for example, Mark Finnane, 'Asylums, Families and the State', History Workshop, 20 (1985), 135. Finnane stretches the doctor/priest metaphor even further to include an equation of the asylum and the church.

75 John Stenhouse, 'Religion and society', in Giselle Byrnes (ed.), The New Oxford History of New Zealand (Melbourne: Oxford University Press, 2009), 343.

76 Warwick Brunton, 'The New Zealand lunatic asylum: conception and misconception', in R.E. Wright-St Clair (ed.), Proceedings of the First New Zealand Conference on the History of New Zealand and Australian Medicine (Hamilton, NZ: Waikato Postgraduate Medical Society, Waikato Hospital, 1987), 162.

77 Knewstubb, op. cit. (note 27), 75, 98-99. 
vital events registers, and digitised newspapers to flesh out important areas of analysis. A good measure of success was achieved, especially in gaining access to searchable external databases for death indexes and digitised online immigration records. How these avenues enriched the research is set out below. Nevertheless, there were inevitable challenges associated with this methodology. A major difficulty related to tracing those with common names but this was alleviated to some extent from other identifying data contained in asylum records, such as age, marital status and so on. The diverse spelling of names posed a further difficulty, while other patients not found may have left the colony. Record linkage also proved time consuming and costly. It was impossible, for example, to trace every patient admitted to Dunedin who had spent time in another asylum. Nevertheless, linking colonial records with imperial institutions and the lives of migrants before their arrival in the colonies reinforced our sense that these histories are part of the larger patterns and narratives of the British world and its histories of mobility and empire. This section focuses on three main areas in which record linkage was pursued.

First, record linkage enabled us to trace prior experiences of committal, often facilitated by the mention of the country or in some cases the asylum in which the migrant was previously admitted. For example, the Protestant Irish woman Mary G entered Seacliff in 1898, but she had been previously confined to a Dublin asylum. The records of the Richmond Asylum in Dublin verify Mary's admission in 1891 when she claimed to be 'a prophetess \& that she is communing with God'. Such cases of prior confinement were of concern because of the possible financial burden to be placed on provincial and central government in New Zealand to provide asylum maintenance, not just immediately after arrival but in respect of long-term or repeat asylum admissions. Indeed, it has been argued that such financial provision in New Zealand, which differed from Britain and Ireland where parishes were responsible for maintaining patients, was a reason for the shipment of the insane. ${ }^{78}$ This raises issues as to the complicity of family, friends and officials in this process and scope for comparative investigation across other colonial sites.

These previous experiences of committal were also connected to issues of heredity, and record linkage enabled us to confirm the admission to asylums in the colony or homeland of family members of Dunedin patients. Used in conjunction with other sources, such linkage can give rich snapshots of patient lives. To take just one example, in December 1893, Patrick F, a 32-year-old married Catholic labourer from 'Aughendea', County Fermanagh, Ireland, was committed to Seacliff Lunatic Asylum, situated less than twenty miles from the city of Dunedin in New Zealand. In a letter he gave to the asylum's superintendent early the following year, Patrick claimed to have 'Landed in this Colony on 3rd October 1877 in the ship James Nicol Fleming at Port Chalmers after 81 days passage from Glasgow'. Patrick's case book entry at Seacliff disclosed that both his mother and sister were in a County Tyrone asylum while his wife divulged that 'one of his brothers was in an Asylum through a cart wheel passing over his head - Another brother was a few months in an Asylum through fright. ${ }^{, 79}$ New Zealand immigration records confirm the details of Patrick's arrival. Returned in the passenger manifest as an 18-year-old farm labourer, Patrick made his journey among a contingent of 101 Irish-born people aged 15 and older. ${ }^{80}$ Meanwhile, the Omagh District Lunatic Asylum records verify the

\footnotetext{
${ }^{78}$ McCarthy, Migration, Ethnicity and Madness, op. cit. (note 10), ch. 2.

79 ANZ Dunedin Regional Office (hereafter DRO), Seacliff Hospital Medical Casebook, DAHI/D264/19956/45, case 2711 (1893).

${ }^{80}$ For Patrick's immigration record and the number of Irish-born people on the vessel, see ANZ Wellington Regional Office, IM 15/295, 16, 37. Patrick was nominated from Otago 3171.
} 
confinement of other family members, though the reasons differ from those in the Seacliff files. In 1884, Patrick's 18-year-old brother Peter F, a labourer with acute mania, entered the Omagh Asylum allegedly for 'Talking foolishly and when bound attempted to beat his father'. Two years later Peter was observed to be 'silent, stupid and sometimes dirty in his habits'. ${ }^{81}$ Discharged in 1887 , he was readmitted two years later. Peter's case book entry reveals a number of claims made about him over the years including occasional violence and slovenliness in his dress, which contrasted with his clean habits and work on the asylum farm. Peter died in the asylum in $1922 .{ }^{82}$ In 1888, another brother Thomas was committed to the Omagh Asylum. According to his committal warrant, he 'did violently assault' his father, a brother was in the asylum, and a sister had died there fourteen years earlier. Thomas was discharged in $1890 .{ }^{83}$ In New Zealand, meanwhile, Patrick F left the asylum in early 1894 but less than a decade later he had drowned at Auckland. In testimony given at the coroner's proceedings, his wife Bridget divulged Patrick's prior admission at Seacliff. ${ }^{84}$

Patrick F's case reveals how record linkage between institutions can flesh out the details of migration and family contexts. Such antecedent aspects were important in shaping migrant experiences abroad. For some asylum patients and their doctors, previous admissions to asylums and the hereditary nature of mental disease were perceived as influential in confinement. Record linkage can also facilitate verification of data found in patient casebooks such as age, the year and ship of arrival, previous asylum admissions of migrants or their family members, and year and place of death. This methodology enables engagement with scholarly critiques that information contained in the casebooks, such as the accuracy of age, is suspect. ${ }^{85}$

Second, record linkage was critical in establishing the transfer of patients between institutions. The practice existed in Britain and Ireland with patients removed from workhouses to asylums or relocated in efforts to secure favourable rates of board. ${ }^{86}$ Similar strategies characterised some transfers in New Zealand. These took several forms. They included individual transfers between asylums including fee-paying families who found Ashburn Hall too expensive and preferred the cheaper option of public asylums. Ashburn Hall's records reveal that of a sample of patients committed there between 1882 and 1909, fifteen per cent were subsequently transferred to Seacliff or other asylums (Wellington, Porirua, Sunnyside, and Nelson) in New Zealand. Perhaps, though, some families or doctors decided on transfers to public funded asylums when all hope of recovery was lost. Patient behaviour as well as finances were therefore prominent in explanations for

\footnotetext{
${ }^{81}$ Various records for Peter's admission in 1884 are: Public Record Office of Northern Ireland (hereafter PRONI), Omagh District Asylum Register of Patients, HOS/29/1/3/4, no. 4057; Committal Papers, HOS/29/1/5/11, no. 4057; and Case book, HOS/29/1/61/1, no. 4057, 81. The Omagh District Lunatic Asylum was later known as the Tyrone and Fermanagh Mental Hospital.

82 Documents relating to Peter's admission in 1889 are: PRONI, Register of Patients, HOS/19/1/3/4, no. 4821; Committal Papers, HOS/29/1/5/14, no. 4821; Case book, HOS/29/1/6/2, no. 4821.

83 PRONI, Committal papers, HOS/29/1/5/14, no. 4754. Also see Register of Patients, HOS/29/1/3/4, no. 4754; and Case book, HOS/29/1/6/2, no. 4754.

${ }^{84}$ A newspaper notice of the inquest is included in Patrick's case record. The paper appears to be the Otago Witness, 10 June 1903. An account also appears in the Auckland Star, 29 May 1903, 4. Patrick was 41 years of age at the time of his death and had four surviving children. See Births, Deaths, and Marriages, 1903/162.

${ }^{85}$ See, for instance, Mills, op. cit. (note 1), 16-24.

${ }^{86}$ Peter Bartlett, 'The asylum and the Poor Law: the productive alliance', 56, and Lorraine Walsh, “ "The property of the whole community". Charity and insanity in urban Scotland: the Dundee Royal Lunatic Asylum, 18051850', 195, in Melling and Forsythe (eds), Insanity, Institutions and Society, op. cit. (note 19).
} 
such transfers. Transfers also took place from public asylums to the private institutions with some families perhaps perceiving the private asylum as offering a better standard of care for patients and a greater likelihood of recovery. Mass transfers between asylums also took place. These usually occurred when asylums became overcrowded or closed, and generated concern from families and friends who would be separated. ${ }^{87}$

Recent research on mental health in the Australasian colonies has highlighted the transfer of some patients between colonial welfare and penal institutions. ${ }^{88}$ Inmates in the asylums came from a variety of other social institutions, or were transferred from prisons. In particular, vagrants, arrested by police under laws controlling and regulating mobility, tended to find themselves caught between institutions for the insane and other institutional confinement including short-term stays in goal. There were also the recipients of welfare relief living in benevolent homes, welfare institutions and religious hostels, in Victoria's immigrants' homes and in homes for the elderly and destitute in Auckland, such as the Costley Home. These transfers show the ongoing mobility of some asylum patients, as well as the important links between types of social institutions. The history of this 'web' of welfare and medical institutions is only partially examined. ${ }^{89}$

Third, linking patient details from the Dunedin public asylums to death certificates proved important in light of the project's sampling procedure where readmissions could be missed or were beyond the scope of access (for those patients whose time in the asylum went beyond the 100-year closure period). This methodology revealed that discharged patients could be readmitted and die in asylums. Indeed reports in 1881 noted that readmissions formed twenty per cent of confinements to New Zealand asylums. ${ }^{90}$ Some patients were admitted to asylums elsewhere in New Zealand where they died. As a sample of patients from the Dunedin and Seacliff asylums reveals, fifty-one per cent ( $n=666)$ died in an asylum in New Zealand. Patient readmissions were also observed by asylum authorities worldwide. At Sligo, Ireland, between 1855 and 1893, a third of patients were committed more than once and, as with those confined to the Dunedin public asylums, half eventually died in the asylum. ${ }^{91}$ Longitudinal record linkage therefore constitutes an important methodological advance in analyses of the asylum, given that many studies generally provide a snapshot of the patient at the time of their admission and during their stay in the institution. By tracing their lives after the asylum, we find that many patients were readmitted to the same or other asylums.

The longitudinal record linkage deployed in our research therefore takes us beyond isolated and often static moments in time that are limited to admission registers, case notes and decadal census data. Deploying this methodology to trace the lives of patients and their families at 'home' and abroad points to exciting transnational and comparative opportunities for scholars of psychiatry using qualitative and quantitative data. It also opens up the possibility of collaboration that merges distinct databases. While there are inevitable challenges associated with this, future collaboration could, for instance, show

\footnotetext{
${ }^{87}$ See McCarthy, Migration, Ethnicity, and Madness, op. cit. (note 10), 106-110.

${ }^{88}$ Catharine Coleborne, 'Regulating "Mobility" and Masculinity through Institutions in Colonial Victoria, 1870s-1890s', Law Text Culture, 15 (2011), 60.

${ }^{89}$ See Coleborne, Insanity, Identity and Empire, op. cit. (note 26), 51-83.

${ }^{90}$ AJHR, 1881, H-13, 2.

${ }^{91}$ McCarthy, Migration, Ethnicity, and Madness, op. cit. (note 10), 109; Elizabeth Malcolm, “"The house of strident shadows": the asylum, the family and emigration in post-Famine rural Ireland', in Elizabeth Malcolm and Greta Jones (eds), Medicine, Disease and the State in Ireland, 1650-1940 (Cork: Cork University Press, 1999), 181.
} 
both the collective experience of migration and mental health and its diversity. It would also facilitate the tracing of migrants across borders, though not necessarily telling us why they moved.

\section{Conclusions}

The focus of this article has been to illuminate the rich potential of psychiatric patient records in a large data sample through its reflection on methodological processes. It also highlights the value of an innovative multi-sited methodology to develop comparative and transnational approaches to medical history. It has suggestively offered examples of the uses of evidence made by a collaborative team, the members of which produced separate and combined research findings guided partly by the content of the sources and their own research interests, and partly by broader historiographical issues. Much more work could be conducted using this data. One of the threats to medical history research of this kind in Australia and New Zealand is the relative paucity of research funding when compared with the United Kingdom. Another aim of this article is to extend our reach into audiences of readers and researchers keen to look at their data using a similar set of approaches, to offer our skills to students, research teams and others. Some preliminary discussions about the future uses of such psychiatric data beyond the life of any funded projects have occurred, and possibilities include imperial and colonial institutional sites.

Our data shows that psychiatric records of the British world could provoke and stimulate much new comparative research into networks and transnational methodologies, the transmission and dissemination of ideas, the mobility of peoples, institutional worlds and more, but we also assert here the value of the different interpretative ideas we have examined. The potential, as well as the limitations, of large data for medical history must both be considered fruitful. Where we have tested ways of understanding and knowing our data - such as through the use of categories of analysis, and record linkage - we hope to incite connections and debate. 